\title{
Depression and Compliance of Fe Tablet Consumption are Combined Risk Factors for Pregnant Women Constipation at Public Health Center Pedurenan, Tangerang City
}

\author{
${ }^{1}$ Putri Ayu Anjani, ${ }^{2 *}$ Khairizka Citra Palupi, ${ }^{3}$ Mertien Sa'pang, ${ }^{4}$ Dudung Angkasa, ${ }^{5}$ Vitria Melani \\ ${ }^{1}$ Nutrition Department, Universitas Esa Unggul, Indonesia, putriayuanjani6@gmail.com \\ ${ }^{2}$ Nutrition Department, Universitas Esa Unggul, Indonesia, khairizka.citra@esaunggul.ac.id \\ ${ }^{3}$ Nutrition Department, Universitas Esa Unggul, Indonesia, mertien.sapang@esaunggul.ac.id \\ *Coresponding author: khairizka citra palupi, e-mail : khairizka.tridharma@ gmail.com
}

\begin{abstract}
Constipation marked by feces hard one, dry, and difficult issued. About 73.9\% pregnant women experience constipation. Increase in the hormone progesterone for pregnant women resulted in drop motility gastrointestinal tract. Constipation affects psychology and causes swelling of the rectum area. To determine the relationship between the fiber adequacy level, compliance of $\mathrm{Fe}$ tablets consumption and depression and to see the combined risk factors for depression and compliance of Fe tablets consumption with the incidence of constipation in pregnant women. Design this research is observational analytics with Cross Sectional design. The sample of pregnant women is 55 people with purposive sampling data collection technique. Taking data done with use questionnaire. Statistic test used the chi-square test. 58.2\% of pregnant women experienced constipation; $92.7 \%$ insufficient fiber sufficiency level; $40.0 \%$ adhered to consuming Fe tablets; 55.4\% experienced depression; 23.6\% of depression was adherent. The results of the chi-square test showed that there was no significant relationship between fiber adequacy level and the incidence of constipation in pregnant women $(\mathrm{p}=0.298)$ and a significant relationship with the incidence of constipation in pregnant women, namely consuming Fe tablets $(\mathrm{p}=0.039$; OR $=$ $4.080)$, depression $(\mathrm{p}=0.026$; $\mathrm{OR}=4.125)$, risk factors for the combination of depression and compliance of Fe tablets consumption $(p=0.005)$. Compliance with Fe tablet consumption and depression can increase the risk of constipation in pregnant women by 4,080 times and 4,125 times.
\end{abstract}

How to cite this article: Anjani, P. A., Palupi, K. Z., Sa'pang, M., Angkasa, D., Melani. (2021). Depression and Compliance of Fe Tablet Consumption are Combined Risk Factors for Pregnant Women Constipation at Public Health Center Pedurenan, Tangerang City. JNS: Journal of Nutrition Science, 2(1), 23-30

\section{Introduction}

Constipation is defined as the frequency of defecate movements less than three times per week. The onset of constipation is characterized by dry feces, hard feces, difficult to pass and usually small in size. Pain during defecate, frequent bloating, cramps stomach and fullness in the stomach are symptoms experienced by some people who constipation (Syamsudin, 2013). Constipation can be classified into two, are constipation is caused structural abnormalities that occur in obstructed fecal flow and constipation is caused functional abnormalities related to excess reabsorption and disorder in colonic motility (Siki, 2020). Pregnant women who constipation if not treated immediately will affect the mother's psychology because it can cause serious complications, such as fecal impaction or obstruction caused by hardened feces. When constipation, the feces is difficult to pass so it is necessary to push too hard during defecate, this can cause swelling in the rectum area to bleed (hemorrhoids), if it occurs in pregnant women it will have an effect during the childbirth process, is not to push too hard during childbirth (Ferdianke et al, 2018; Shi et al. 2015).

Several researchers previously showed the prevalence of constipation in pregnant women in 
different regions, amounting to $13.01 \%$ in Shanghai (Shi et al. 2015). Research in Indonesia showed a greater incidence of constipation, namely $54.4 \%$ in pregnant women in Bandar, Pacitan Regency (Wulan and Fitria, 2018), 56.7\% in pregnant women in Lamongan Regency (Rahayu et al. 2010) and 35.7\% in pregnant women in Lamongan (Kartikasari and Payana, 2017). Factors related to constipation in pregnant women include diet, lifestyle, psychology, physical activity, fluid intake, fiber intake, knowledge and irregular defecation habits are factors that can be changed. Meanwhile, changes in the digestive tract, consumption of Fe tablets, increased hormones, suppression of the rectum, gestational age, socioeconomic and socio-cultural factors cannot be changed (Drossman and Dumitrascu, 2006; Cox et al. 1987).

Studies in Indonesia that researching the fiber adequacy level, $\mathrm{Fe}$ tablets consumption, and depression associated with the incidence of constipation in pregnant women are still very limited and there are differences in analysis results from various literature regarding fiber intake and adherence to consumption of Fe tablets and there is no research on the incidence of constipation associated with depression in pregnant women. This study focuses on pregnant women because during pregnancy there are many changes as such in physical, mood and hormonal changes. One of the complaints that are felt during pregnancy is constipation. Therefore, this study includes several factors that are complex at risk of causing constipation in pregnant women. Thus, the aim of this study was to analyze the relationship between fiber adequacy levels, compliance with $\mathrm{Fe}$ tablet consumption and depression with the incidence of constipation in pregnant women. In addition, this study also looked at the combination risk factors of depression and compliance with $\mathrm{Fe}$ tablet consumption that affect the incidence of constipation in pregnant women at Pedurenan Public Health Center, Tangerang City.

\section{Material and Method Design and Subject}

Type of research is an observational study with quantitative methods using a cross-sectional design. This research was conducted at the Pedurenan Public Health Center, Tangerang City, starting from on July to the end on July 2020. The sampling method used was purposive sampling in suitable with the inclusion and exclusion criteria. The inclusion criteria were pregnant women who checked their uterus at the Pedurenan Public Health Center and were willing to take part in the research. The exclusion criteria used were difficulty communicating, gestational age entering 39 weeks, incidence of constipation due to other diseases such as colon cancer, diabetes mellitus, hyperthyroidism, etc. Based on respondents' statements and physical disabilities. The population of pregnant women at the Pedurenan Public Health Center was 102 people. The sample is calculated based on the 2 proportion test sampling formula using a significance level of $5 \%$ and a test power of $95 \%$, then the number of samples taken to be used as research respondents is 55 people. This research has received a letter of statement from the Tangerang City Health Office and a letter of statement of passing ethics from Esa Unggul University, Faculty of Health Sciences number: $\quad$ 0022-19.530/DPKE-KEP/FINALEA/UEU/I/2020.

\section{Data Collection and Measurement}

The dependent variable studied was the incidence of constipation, while the independent variable studied was the fiber adequacy level, compliance of Fe tablet consumption and depression.

Constipation. Constipation data were obtained through filling out the Rome III Criteria questionnaire. The Rome criteria is an effort that can assist in the diagnosis and treatment of functional digestive disorders such as intestinal, anorkal, and gastroduodenal disorders, consisting of 7 questions including feeling bowel movements accompanied by strong straining, defecating accompanied by hard stools, feeling dissatisfied after defecating, feeling the sensation of blockage in the anus after defecating, using manual measures such as using fingers / prying up the pelvic cavity, frequency of defecation less than 3 times a week, and not meeting the criteria for irritable bowel syndrome such as abdominal pain, ulcers, inflammation of the pancreas and inflammation of the intestine. Assessment of the incidence of constipation is positive ( + ) if there is an answer (yes) to 1 or more questions 1-4 or 2 or more of all questions and negative (-) if there is an answer (no) to all questions (Drossman and Dumitrascu, 2006).

Fiber Adequacy Level. The fiber adequacy level was obtained through a $2 \times 24$ hour food-recall interview, one weekday and one weekend day. The food-recall data is then processed using Nutrisurvey 2007 software. The results of the calculation of fiber intake are compared with the nutritional adequacy rate (RDA) in 2019 plus additional fiber for pregnant 
women per trimester. Data on fiber intake were categorized into 2 categories, namely less if $<77 \%$ RDA and sufficient if $>77 \%$ RDA (Gibson, 2005). Depression. Depression data were obtained through filling out the Edinburgh Postnatal Depression Scale questionnaire, which is a depression screening tool. Consists of 10 questions covering being able to laugh and see from a funny point of view, being happy to face everything or doing everything fun, blaming yourself, feeling anxious and worried for reasons that are not clear, feeling scared or panicking for reasons that are not clear, all something feels burdensome, sad and unhappy so that it is difficult to sleep, feels sad or irritated uncertainly, sad and unhappy so that we cry and never have thoughts of hurting oneself. The maximum EPDS score is 30 with normal 0-9 intervals, and the possibility of depression if the total score is $\geq 10$. A score of 10-12 indicates a moderate risk of depression. A score of 13-30 indicates a risk of major depression (Cox et al. 1987).

Compliance with $\mathrm{Fe}$ Tablets Consumption. Compliance data for $\mathrm{Fe}$ tablet consumption was obtained using a questionnaire consisting of 6 questions including during pregnancy consuming $\mathrm{Fe}$ tablets, how many Fe tablets received each month, gestational age when consuming Fe tablets for the first time, Fe tablets consumed every month, the remaining $\mathrm{Fe}$ tablets that are not consumed every month, the thing that makes it disobedient to consume Fe tablets. Adequacy is measured by the percentage of the calculation of the number of iron tablets consumed compared to the number of $\mathrm{Fe}$ tablets that should be consumed by pregnant women. Pregnant women are said to be obedient if the score is $\geq 90 \%$, if the score is $<90 \%$, it is said that they are not obedient to consuming Fe tablets (Bongga et al. 2006).

\section{Data Analysis}

The data analysis performed were univariate and bivariate. The bivariate analysis used the Chi-Square test to determine the relationship between the fiber adequacy level, compliance of $\mathrm{Fe}$ tablets consumption and depression with constipation variables, all of which were categorical scales. Data were analyzed using SPSS version 20.

\section{Results}

The results of the analysis showed that the proportion of constipation among pregnant women at the Tangerang City Health Center was $58.2 \%$. Based on the characteristics of respondents in Table 1, it can be seen that the majority of pregnant women are aged 22-35 years $(63.6 \%)$ with gestational age in the third trimester (50.9\%). Pregnant women with insufficient fiber adequacy level (92.7\%), obedient in consuming Fe tablets (40.0\%), experienced depression (55.4\%) and the risk factors for the combination of depression were disobedient $(70.9 \%)$.

Tabel 1. Respondent Characteristic $(n=55)$

\begin{tabular}{|c|c|c|}
\hline \multirow[t]{2}{*}{ Variable } & \multicolumn{2}{|c|}{ Amount } \\
\hline & $\mathbf{n}$ & $\%$ \\
\hline \multicolumn{3}{|l|}{ Age } \\
\hline$<25$ years old & 14 & 25,5 \\
\hline 25-35 years old & 35 & 63,6 \\
\hline$>35$ years old & 6 & 10,9 \\
\hline \multicolumn{3}{|l|}{ Gestational Age } \\
\hline $1^{\text {st }}$ Trimester & 8 & 14,5 \\
\hline $2^{\text {nd }}$ Trimester & 19 & 34,5 \\
\hline $3^{\text {rd }}$ Trimester & 28 & 50,9 \\
\hline \multicolumn{3}{|c|}{ Incidence of Constipation } \\
\hline Constipation & 32 & 58,2 \\
\hline Not Constipation & 23 & 41,8 \\
\hline \multicolumn{3}{|l|}{ Depression } \\
\hline Depression & 30 & 55,4 \\
\hline Not Depression & 25 & 45,5 \\
\hline \multicolumn{3}{|c|}{ Compliance of Fe Tablet Consumption } \\
\hline Obedient & 22 & 40,0 \\
\hline Disobedient & 33 & 60,0 \\
\hline \multicolumn{3}{|c|}{ Fiber Adequacy Level } \\
\hline Insufficient & 51 & 92,7 \\
\hline Sufficient & 4 & 7,3 \\
\hline \multicolumn{3}{|c|}{$\begin{array}{l}\text { Combination Risk Factors for Depression and } \\
\text { Compliance of Fe Tablet Consumption }\end{array}$} \\
\hline $\begin{array}{l}\text { Depression and } \\
\text { obedient }\end{array}$ & 13 & 23,6 \\
\hline $\begin{array}{l}\text { Not Depression } \\
\text { and Obedient }\end{array}$ & 9 & 40,0 \\
\hline $\begin{array}{l}\text { Depression and } \\
\text { Not Depression }\end{array}$ & 17 & 70,9 \\
\hline $\begin{array}{l}\text { Not depression and } \\
\text { Disobedient }\end{array}$ & 16 & 29,1 \\
\hline
\end{tabular}

Table 2 showed a significant relationship $(\mathrm{p}<0.05)$ between depression $(\mathrm{p}=0.026$; $\mathrm{OR}=4.125 ; 95 \% \mathrm{CI}$ $=1,322-12,872)$ and compliance of $\mathrm{Fe}$ tablets consumption $(\mathrm{p}=0.039 ; \mathrm{OR}=4.080 ; 95 \% \mathrm{CI}=$ $1,217-13,680)$ with the incidence of constipation in pregnant women, but there was no significant relationship between the fiber adequacy level and the incidence of constipation in pregnant women $(\mathrm{p}=$ 0.298 ; $\mathrm{OR}=4,650 ; 95 \% \mathrm{CI}=0.452-47.885)$. The results of the analysis of the other chi-square test showed a significant relationship regarding the combination of risk factors for pregnant women who 
experienced depression and were adherent in consuming $\mathrm{Fe}$ tablets with a higher risk of experiencing constipation with a $\mathrm{P}$-value of 0.005 $((<) 0.05)$.

Tabel 2. Relationship between Depression, Compliance of Fe Tablet Consumption and Sufficient Level of Fiber with Incidence of Constipation in Pregnant Women at Pedurenan Public Health Center, Tangerang City

\begin{tabular}{|c|c|c|c|c|c|}
\hline \multirow{3}{*}{ Variable } & \multicolumn{2}{|c|}{ Incidence of Constipation } & \multirow[t]{2}{*}{ Amount } & \multirow[t]{3}{*}{ P-value } & \multirow{3}{*}{$\begin{array}{c}\text { OR } \\
\text { (95\% Confidence } \\
\text { Interval) }\end{array}$} \\
\hline & Constipation & $\begin{array}{c}\text { Not } \\
\text { Constipation }\end{array}$ & & & \\
\hline & $\%$ & $\%$ & $\mathrm{~N}$ & & \\
\hline
\end{tabular}

Relationship between Depression with Incidence of Constipation

\begin{tabular}{|c|c|c|c|c|c|c|c|c|}
\hline Depression & 22 & 40,0 & 8 & 14,5 & 30 & 54,5 & 0,026 & $4.125(1.322-12.872)$ \\
\hline Not Depression & 10 & 18,2 & 15 & 27,3 & 25 & 45,5 & & \\
\hline
\end{tabular}

\section{Relationship between Compliance of Fe Tablet Consumption with Incidence of Constipation}

\begin{tabular}{lcccccccc}
\hline Obedient & 17 & 30,9 & 5 & 9,1 & 22 & 40,0 & 0,039 & $4.080(1.217-13.680)$ \\
\cline { 1 - 5 } Disobedient & 15 & 27,3 & 18 & 32,7 & 33 & 60,0 & &
\end{tabular}

\begin{tabular}{|c|c|c|c|c|c|c|c|c|}
\hline \multicolumn{9}{|c|}{ Relationship between Fiber Adequacy Level with Incidence of Constipation } \\
\hline Insufficient & 31 & 56,4 & 20 & 36,4 & 51 & 92,7 & \multirow{2}{*}{0,298} & \multirow[t]{2}{*}{$4.650(0,452-47.885)$} \\
\hline Sufficient & 1 & 1,8 & 3 & 5,5 & 4 & 7,3 & & \\
\hline
\end{tabular}

\section{Combination Risk Factors for Depression and Compliance of Fe Tablet Consumption}

\begin{tabular}{|c|c|c|c|c|c|c|c|}
\hline $\begin{array}{l}\text { Depression and } \\
\text { obedient }\end{array}$ & 13 & 23,6 & 0 & 0 & 13 & 23,6 & \multirow{4}{*}{0,005} \\
\hline $\begin{array}{l}\text { Not Depression and } \\
\text { Obedient }\end{array}$ & 4 & 7,3 & 5 & 9,1 & 9 & 16,4 & \\
\hline $\begin{array}{l}\text { Depression and Not } \\
\text { Depression }\end{array}$ & 9 & 16,4 & 8 & 14,5 & 17 & 30,9 & \\
\hline $\begin{array}{l}\text { Not depression and } \\
\text { Disobedient }\end{array}$ & 6 & 10,9 & 10 & 18,2 & 16 & 29,1 & \\
\hline
\end{tabular}

\section{Discussion}

\section{Respondent Characteristics}

The results of this study indicate the prevalence of constipation in pregnant women at Pedurenan Public Health Center in Tangerang City is $58.2 \%$. The proportion rate in this study is higher than the four previous studies (Wulan and Fitria, 2018; Cheng et al. 2003). The majority of pregnant women $(40.0 \%)$ stated that they felt there were blockages in the intestines such as flatulence, constipation and difficulty passing gas. Other symptoms of constipation felt by pregnant women were feeling defecating accompanied by strong straining and accompanied by a sense of incomplete excretion (27.3\%); experienced defecation accompanied by hard stools (25.5\%); frequency of defecation less than 3 times a week (21.8\%); do not feel there are criteria for irritable bowel syndrome (16.4\%) and pregnant women use manual measures when defecating such as using fingers and sticking out the stomach (5.5\%).

Factors Associated with The Incidence of Constipation

The results showed that there was no significant relationship in the variable fiber adequacy level, but there were two other variables that showed a significant relationship with the incidence of constipation, namely compliance of $\mathrm{Fe}$ tablets consumption and depression.

This study found that pregnant women who felt depressed had a greater proportion of experiencing constipation than those who were not depressed. There is a significant relationship between depression and constipation in pregnant women. Pregnant women 
who feel depressed are 4,124 times more likely to experience constipation than pregnant women who do not experience depression.

This study is in line with the results of a study of pregnant women at the Shanghai China Hospital, that pregnant women face more emotional stress and changes in their environment which are also important causes of constipation. Some pregnant women feel negative emotions such as irritability, anxiety, tension, depression and anger, which can lead to neurological disorders. So it is known that the analysis in this study shows that emotional, stress and low mood are risk factors for functional constipation during pregnancy (Wulan and Fitria, 2018). The effect of stress is found in humans who feel anxiety, fear and have pressure. Stress and emotions can strongly influence the work of the colon. The colon has many nerves associated with the brain. The colon is partly controlled by the sympathetic nervous system which responds to stress (Hayati, 2020; Hanifa, 2011).

This can be seen in the results of this study that the factors that cause pregnant women to experience depression during the last 1 month because many pregnant women feel anxious and worried for reasons that are not clear at $54.6 \%$, other questions with a percentage of $54.6 \%$ are also felt. Pregnant women are sad or upset uncertain, some pregnant women often or sometimes blame themselves if there is an error of $49.1 \%$. Pregnant women who feel frightened or panicked for reasons that are not clear are $47.3 \%$, pregnant women sometimes feel sad and unhappy so that it is difficult to sleep by $41.9 \%$, pregnant women feel sad and unhappy so they cry $25.45 \%$ of pregnant women who sometimes feel helpless over everything that pleases them is $21.8 \%$, and $3.6 \%$ of pregnant women rarely laugh from funny aspects and have in the mind of pregnant women to hurt themselves.

This can be seen in the results of this study that the factors that cause pregnant women to experience depression during the last 1 month because many pregnant women feel anxious and worried for reasons that are not clear at $54.6 \%$, other questions with a percentage of $54.6 \%$ are also felt. Pregnant women are sad or upset uncertain, some pregnant women often or sometimes blame themselves if there is an error of $49.1 \%$. Pregnant women who feel frightened or panicked for reasons that are not clear are $47.3 \%$, pregnant women sometimes feel sad and unhappy so that it is difficult to sleep by $41.9 \%$, pregnant women feel sad and unhappy so they cry $25.45 \%$ of pregnant women who sometimes feel helpless over everything that pleases them is $21.8 \%$, and $3.6 \%$ of pregnant women rarely laugh from funny aspects and have in the mind of pregnant women to hurt themselves.

It is known that stress can affect defecation, psychological stress can affect digestive function through the brain-gut connection, such as upset stomach and irritable bowel syndrome. It is also known that people who are depressed can slow down intestinal motility, which can lead to constipation (Tjay and Kirana, 2003; Sulistyawati, 2009). Strong emotions are thought to cause constipation by inhibiting intestinal peristalsis through the action of epinephrine and the sympathetic nervous system. Stress can also cause a spastic intestine. With hypertonic constipation or colonic irritation, there is a period of abdominal cramping, an increase in the number of mucus and a period of alternating between diarrhea and constipation. It can all be caused by stress or depression (Cox et al. 1987). Anxiety and other mental factors affect the hypothalamus and autonomic nervous system, which weakens the tension of the digestive tract, reduces the secretion of digestive juices in the digestive tract, slows down the transmission of feces and dries the stool (Fan et al. 2020).

Furthermore, the results of this study indicate a significant relationship between compliance with $\mathrm{Fe}$ tablet consumption with the incidence of constipation in pregnant women. Pregnant women who adhere to consuming Fe tablets have a 4.080 times greater risk of experiencing the incidence of constipation compared to pregnant women who are not adherent to consuming Fe tablets. This study is similar to the results of a study of pregnant women at Payung Sekaki Public Health Center, Pekanbaru. It shows a significant relationship between the effect of Fe tablet consumption and the incidence of constipation in pregnant women. Researchers stated that the incidence of constipation was more likely in pregnant women who consumed Fe tablets regularly (Hayati, 2020). This is also in line with research in Bandar Village, Bandar District, Pacitan Regency, which shows a significant relationship between consuming Fe tablets and the incidence of constipation in pregnant women. So it is known that regular consumption of Fe tablets is closely related to the incidence of constipation in pregnant women (Rahayu et al. 2010).

Based on the results of interviews with pregnant women regarding the consumption of Fe tablets taken during pregnancy, it was found that $47(85.5 \%)$ consumed Fe tablets and $8(14.5 \%)$ did not consume Fe tablets. Every month, pregnant women receive 30 tablets of Fe tablets from public health centers 21 
(38.2\%), midwives $21(38.2 \%)$ or doctors $5(9.1 \%)$. On average pregnant women consume $\mathrm{Fe}$ tablets starting in early pregnancy, namely when trimester I was $36(65.5 \%)$, trimester II was $10(18.2 \%)$, trimester III was $1(1.8 \%)$, and had not consumed it. Fe tablet as much as $8(14.5 \%)$. Pregnant women are considered obedient in consuming $\mathrm{Fe}$ tablets if in the first trimester pregnant women consume as many as 30 tablets, in the second trimester they consume 60 tablets and in the third trimester they consume 90 tablets, because during pregnancy, pregnant women must consume at least 90 tablets. Pregnant women are not obedient in consuming Fe tablets, usually there are still remaining Fe tablets every month, this is because pregnant women forget (18.2\%), are lazy $(12.7 \%)$, nauseous $(5.5 \%)$ and do not like it. medicine $(1.8 \%)$. Iron or $\mathrm{Fe}$ supplements cause bowel movement disorders so that waste products of food waste (feces) contract the colonic muscles pushing stool into the rectum. Once it reaches the rectum the stool is solid because most of the water will be absorbed. Hard, dry stool results from the colon absorbing too much water. This occurs because the colonic muscles contract too slowly and cause the stool to move towards the colon for too long. Iron has a contractionary effect and acts more locally on the intestinal mucosa to cause constipation. This effect can be reduced by consuming $\mathrm{Fe}$ tablets within the overdosed dose limit for consumption during pregnancy (Cox et al. 1987; Hestiantoro and Baidah, 2018).

The iron content contained in Fe tablets is very high so that if consumed it will be absorbed which can cause the acidity level of the intestine to increase. Partially absorbed Fe tablets will be bound by intestinal mucosal cells causing an acidic environment reaction in the intestine, this can cause the intestine to work less efficiently resulting in constipation (Tjay and Kirana, 2003). Doses of iron above $60 \mathrm{mg}$ can cause unacceptable side effects in pregnant women so that there is non-compliance in the use of Fe tablets, with low doses of 30-60 mg more likely to be tolerated (taken) than high doses (Sulistyawati, 2009). Constipation can also be relieved by increasing drinking 8-10 glasses / day, increasing the intake of foods high in fiber such as cereals, bread and jelly and limiting iron supplements to not every day but 2 days a day with a record of iron-rich foods. (eg animal meat) should be added, which is eaten on the day when the supplement is not given (Arisman, 2010).

The average intake of food consumed by respondents every day contains as much as 5.6 to 27.7 grams of fiber. The results of the analysis show that there is no significant relationship between the fiber adequacy level and the incidence of constipation in pregnant women. This result is in line with a study conducted at the Palembang Clinic that fiber intake did not have a significant relationship with the incidence of constipation (Anisa et al. 2018) and in line with a study in Jakarta which reported that there was no significant relationship between fiber intake and the incidence of constipation (Hestiantoro and Baidah, 2018).

This situation is probably because the average fiber intake of respondents in this study is still very lacking compared to the 2019 RDA so that it is unable to provide a meaningful relationship. Fiber intake data tends to be homogeneous because most of the $92.7 \%$ of pregnant women have not fulfilled their fiber needs based on the RDA for women aged 16-49 ranging from 29-32 grams per day, for pregnant women get a little more fiber intake. In the first trimester, you get 3 grams of fiber, the second and third trimester you get 4 grams of fiber. The addition of fiber depends on the age of the pregnant woman plus her gestational age (Kemenkes RI, 2013).

Based on research that shows the results of a $2 \times 24$ hours recall, it is known that pregnant women consume more food from animal sources. Most often consumed for 2 days by pregnant women such as fried fish 31 (21.4\%), milk 30 (20.7\%), eggs 29 (20\%), and fried chicken $26(17.9 \%)$. Pregnant women also often consume vegetable source foods, such as fried tempeh 29 (20.0\%), fried tofu $17(11.7 \%)$, and green bean porridge $9(6.2 \%)$. Consumption of vegetables and fruits is also consumed by pregnant women for 2 days, vegetables most often consumed by pregnant women are spinach 27 (18.6\%), vegetable soup $14(9.7 \%)$, stir-fried kankung $11(7,6 \%)$ and capcay $7(4.8 \%)$. Meanwhile, the fruits most often consumed by pregnant women for 2 days were 25 bananas (17.2\%), 21 papayas (14.5\%), 12 oranges $(8.3 \%)$, and 11 mangoes (7.6\%).). Types of carbohydrates most often consumed by pregnant women for 2 days are bread 28 (19.3\%), chicken porridge 19 (13.1\%), rice uduk 12 $(8.3 \%)$ and ketupat sayur $5(3.4 \%)$.). While the most types of snacks consumed by pregnant women for 2 days were biscuit $26(17.9 \%)$, bakwan 12 (8.3\%), and lontong filled with vegetables $10(6.9 \%)$.

The $2 \times 24$ hour recall results show that even though pregnant women consume vegetables and fruit every day, it is possible that the fruits and vegetables consumed are small in number, so even though they are often consumed, the amounts are still small, the results of the nutritional analysis will still be 
insufficient and the type of food also affects fiber intake. It is known that in this study the vegetables that are mostly consumed by pregnant women are spinach, chicken soup, capcay and tamarind vegetables which have low fiber content, while fruits that are often consumed by pregnant women such as watermelon, melon, grapes are low in fiber.

There are several reasons that cause the mother's fiber intake to be insufficient, namely some pregnant women feel no appetite because they are experiencing nausea and some feel like eating too much. Another reason is that some pregnant women prefer to consume foods that are fried, fried, coconut milk, animal source foods and milk, causing excess fat compared to high fat, seen in the recall results of foods that are more frequently consumed, such as fried fish, milk, tempe. fried, fried chicken, uduk rice and vegetable ketupat. This results in lower fiber intake and higher fat content.

Furthermore, the results of the research on the combination factor of compliance with $\mathrm{Fe}$ tablet consumption and depression showed that there was a significant relationship between the combined risk factors for depression and compliance with $\mathrm{Fe}$ tablet consumption with the incidence of constipation in pregnant women at Pedurenan Public Health Center, Tangerang City with a P-value of $0.005((<) 0.05)$. So it can be said that although each of the variables of depression and compliance with $\mathrm{Fe}$ tablet consumption is significant, when the risk factors for compliance with $\mathrm{Fe}$ tablet consumption and depression are combined into one standard, the results of the significance will be higher or tighter. So that these two things need to be considered in pregnant women and it is advisable to avoid pregnant women who experience constipation.

In the study, it can be identified that pregnant women are obedient to consuming $\mathrm{Fe}$ tablets because pregnant women are aware that Fe tablets can prevent anemia and bleeding. However, pregnant women are less aware of the side effects of Fe tablets. Pregnant women who consume Fe tablets during pregnancy should be accompanied by sufficient water consumption of $>8$ glasses / day so that they can stimulate natural intestinal contractions and sufficient fiber intake of 34-36 grams, equivalent to consuming staple foods (3-4 servings) such as eating 3 ladle rice or 2 medium potatoes and vegetable side dishes (3-4 servings) such as consuming 2 medium pieces of tempeh, tofu $1 / 2$ medium fruit, 5 tbsp green beans. For vegetables and fruit consumed as much as 5-6 servings, vegetables consumed such as 5 tablespoons oyong, 1 plate of long beans, 1 cup of spinach, 1 cup of vegetable soup, 1 plate of green mustard, 1 cup of tamarind vegetables. Meanwhile, the fruits consumed are 2 medium oranges, $1 / 2$ mango, 1 banana, 1 large slice of papaya, 1 small apple, and $1 / 2$ medium pear. In addition, pregnant women who experience constipation are caused by depression because many pregnant women feel anxious and worried for reasons that are not clear, in the study there were more pregnant women in the third trimester of pregnancy so that many pregnant women thought about the time of delivery, especially for pregnant women who gave birth to her first child who has never experienced labor.

\section{Conclusion and Suggestion}

The prevalence of constipation among pregnant women at Pedurenan P Health Center was quite high $(58.2 \%)$. The adequate level of fiber intake is classified as insufficient, many pregnant women experience depression and are obedient to consuming Fe tablets. Compliance with Fe tablet consumption and depression increased the risk of constipation in pregnant women by 4,080 times and 4,125 times greater than those who did not adhere to consuming $\mathrm{Fe}$ tablets and were not depressed. Pregnant women who experience constipation should consume adequate fiber intake based on the RDA by consuming fiber source foods in the portion that suits their needs and can choose foods high in fiber, besides that pregnant women also understand more about $\mathrm{Fe}$ tablets consumed during pregnancy that Fe tablets have an effect. side so that the need to know how to consume Fe tablets is good, that is accompanied by adequate intake of fiber and fluid sources and pregnant women must be able to maintain their mental health which can cause depression during pregnancy, it is preferable to do physical activity or light exercise that can help maintain health physical, mental and launch metabolism.

Suggestions for future research are that it is estimated that there are still other factors that influence the incidence of constipation, therefore it is hoped that further researchers can examine more comprehensively the factors that influence the incidence of constipation in pregnant women, especially physical activity factors because physical activity is associated with constipation and depression which can helps smooth intestinal peristaltic and also helps maintain mental health so that it can be studied in future researchers. 


\section{Acknowledgement}

Thank you to Pedurenan Public Health Center, Tangerang City for being willing to provide space for research. This manuscript has been followed in Batch III Scientific Article Writing Training (SAWT), GREAT 4.1.e Work Program, Undergraduate Nutrition Study Program, Faculty of Health Sciences, Esa Unggul University with the support of facilitators: Dudung Angkasa, S.Gz., M.Gizi, RD; Khairizka Citra Palupi, S.Gz., M.S; Laras Sitoayu, S.Gz., M.K.M, RD, along with a team of other Nutrition Science study program lecturers. SAWT Batch III also received financial support from Esa Unggul University (24).

\section{References}

Anandita, N.S. (2015). Irritable Bowel Syndrome. Med J Lampung Univ. 4:2.

Anisa N., Husin, S., Syarif, S. (2018). Pravelensi dan Faktor Risiko Klinik Al-Syifa Kota Palembang Tahun 2018. Journal of Chemical Information and Modeling.

Angkasa, D., K.Palupi LS et al. Program Kerja U GO GREAT (Vol.1) [Internet]. Perpustakaan Universitas Esa Unggul. 2020. Available from: http://diglib.esaunggul.ac.id/program-kerja-ugo-great-program-studi-s1-ilmu-gizi17032.html

Arisman, B. (2010). Buku Ajar Ilmu Gizi: Gizi Dalam Daur Kehidupan. Jakarta: EGC.

Bongga, Ordenes, D.C., Maria, C.A. (2006). Factors Influencing Compliance With Iron Supplementation Among Pregnant Women. Soc Sci Diliman. 3:1-2:84-107: Mexico City.

Cheng, C., Chan, AOO,. Hui, W.M., Lam, S.K. (2003). Coping strategies, illness perception, anxiety and depression of patients with idiopathic constipation: A population-based study. Aliment Pharmacol Ther. 18(3):319-26.

Cox, J.L., Holden, J.M., Sagovsky, R. (1987). Detection of Postnatal Depression: Development of the 10-item Edinburgh Postnatal Depression scale. Br J Psychiatry.

Drossman, D.A., Dumitrascu, D.L. (2006) Rome III: New standard for functional gastrointestinal disorders. J Gastrointestin Liver Dis. 3:237-41.

Fan, W., Kang, J., Xiao, X., Li, L., Yang X. (2020). Causes of constipation during pregnancy and health management. Int $J$ Clin Exp Med. 13(3)2022-2026. 2020;/ISSN:1940.

Ferdinande, K, Y, Dorreman., K, Roelens., W, Ceelen,
D, De Looze. (2018). Anorectal symptoms during pregnancy and postpartum: a prospective cohort study. Color Dis.

Gibson, R.S. (2005). Principles Of Nutritional Assessment. United States of America: Oxford University Press.

Hanifa, M. (2011). Perkembangan Ibu Hamil dari Konsepsi Sampai Melahirkan. Bandung: Makrifat Media Utama.

Hayati, S. (2020). Pengaruh Konsumsi Tablet Fe dengan Kejadian Konstipasi Pada Ibu Hamil di Puskesmas Payung Sekaki Pekanbaru. J Med Usada. 3:1, Febru.

Hestiantoro, A., Baidah, P.A. (2018). The Prevalence and Risk Factors of Constipation in Pregnancy. Indones J Obstet Gynecol. ;84.

Irianto, K. (2014). Gizi Seimbang dalam Kesehatan Reproduksi. Bandung: Alfabeta.

Kartikasari, R.I., Payana, S.H.D. (2017). Pregnancy Exercises Dengan Kejadian Konstipasi Pada Ibu Hamil Trimester II. Surya. 09(01):54-60.

Kemenkes RI. Permenkes Nomor 75 Tahun 2013 tentang Angka Kecukupan Gizi yang Dianjurkan Bagi Bangsa Indonesia. Kementerian Kesehatan Republik Indonesia. 2013.

Rahayu, D.A.P., Ummah, F., Juanita, F. (2010). Hubungan Pola Makan Ibu Hamil dengan Kejadian Konstipasi di BPS Aida Hartatik Desa Ndalanggu Kecamatan Deket Kabupaten Lamongan. Surya.

Shi W, Xu X, Zhang Y, Guo S, Wang J, Wang J. (2015). Epidemiology and risk factors of functional constipation in pregnant women. PLoS One. 10(7):1-10.

Siki, D.A.N. (2020). Asuhan Keperawatan Konstipasi dengan Pendekatan $3 S$ (Sdki, Slki Dan Siki).

Sulistyawati, A. (2009). Asuhan Kebidanan Pada Masa Kehamilan. Jakarta: Salemba Medika.

Syamsudin. (2013). Farmakoterapi Gangguan Saluran Pencernaan. Jakarta: Buku Kedokteran EGC.

Wulan, C., Fitria, W.A. (2018). Hubungan Mengkonsumsi Tablet Fe dengan Kejadian Konstipasi Pada Ibu Hamil di Desa Bandar Kecamatan Bandar Kabupaten Pacitan. $J$ Delima Harapan.

Tjay, T. H dan Kirana R. (2003). Obat-Obat Penting. Jakarta: Pt Elex Media Komputindo. 